\title{
Platelets, Pecam1 Gene, Thromboxane Genes, in Invertebrates
}

\author{
Michel Leclerc \\ 556 rue Isabelle Romée, 45640 Sandillon (France) \\ *Corresponding Author: Michel Leclerc, 556 rue Isabelle Romée, 45640 Sandillon (France)

\section{ABSTRACT} \\ Three main points assert the evidence: of «platelets » in Echinodermata (Asterids, Ophuirids and Crinoïds \\ (Invertebtates), of a new cytokine (Thromboxane A2) : \\ a) the evidence of thromboxane genes. \\ b) the appearance of T.E.M platelets, in the asterid, Asterias rubens. \\ c) the presence of PECAM1 gene in ophuirids and crinoïds.
}

\section{INTRODUCTION}

The appearance of platelets, in Asterias rubens has been described (Ref.1 Fig 1) in invertebrates: They resemble blood platelets of vertebrates.

In the present work, we recall genes which are implicated in the physiology of vertebrate platelets:

Thromboxane A synthetase gene, Thromboxane A2 receptor gene, Pecam1 gene are the main genes which represent thromboxane activity in vertebrates.

This study reports T.E.M observations of sea star platelet, genomic research of Thromboxane genes and Pecam1 gene in Echinodermata genomes

\section{Materials ANd Methods}

1) Ophiocomina nigra and Antedon bifida were purchased by the Laboratory of Roscoff (France). Digestive coeca were excised.RNA was extracted.

\begin{tabular}{|c|c|c|c|c|c|c|c|c|c|}
\hline Query ID & $\begin{array}{l}\text { Query } \\
\text { Name }\end{array}$ & Subject ID & $\frac{\text { Identity }}{(\%)}$ & Length & Mismatch & Gapopen & $\begin{array}{l}\frac{\text { Query }}{\text { cover }} \\
\end{array}$ & E-value & Bitscore \\
\hline $\begin{array}{c}\text { NM_00106 } \\
0.5\end{array}$ & TBXA2R & $\begin{array}{l}\text { TRINITY_D } \\
\text { N38594_c0_ } \\
\text { g1_i1 }\end{array}$ & 77,93 & 222,00 & 34,00 & 9,00 & $\overline{13,00}$ & $2,00 \mathrm{E}-27$ & 124,00 \\
\hline $\begin{array}{c}\mathrm{NM}_{1.0} 00106 \\
\end{array}$ & TBXAS1 & $\begin{array}{c}\text { TRINITY_D } \\
\text { N22549_c0_ } \\
\text { g1_i1 }\end{array}$ & 84,21 & 38,00 & 6,00 & 0,00 & 2,00 & $1,60 \mathrm{E}-01$ & 38,10 \\
\hline
\end{tabular}

The sequence of the TBXA2R transcrriptome is following :

>TRINITY_DN38594_c0_g1_i1
2a)Ophiocomina nigra and Antedon bifida mRNA were obtained ( Ref.2) .Furthermore quality controls were made.

2b) Sequencing : Transcriptome was assembled from RNA-Seq fastq files using Trinity v2.1.1 ( Ref.3 )with default parameters. A BLAST database was created with the assembled transcripts using makeblastdb application from ncbi-blast+ (v2.2.31+). The sequences of transcripts of interest were then blasted against this database using blastn application from ncbiblast+ ( Ref .4) with parameter word_size 7.

\section{RESUlts}

We observe a sea star Asterias rubens platelet in T.E.M (Ref.1, Fig.1) Evidence of Platelets in Echinodermata

On the other hand, a table summarizes the genomic results. TBXA2R represents the human thromboxane A2 receptor gene, TBXAS1 the human synthetase one 
TATCATATATAATTTTTTTTTAGACAGAATC TTGTCCTGTTGCACAGGGTGGGGTACAAT GGCGCCATCTTTGCTCACTGCAACTTCTG CCTCACGGGTCCAAGCGATTGTCCTCCCT CA

GCCTCCCAGGTAGCTGGGACTACACCAC ACTGGGACTACACCAGCTGCCACCATGC CTAG

CTAATTTTTGTATTTTTGGTAGAGACAGG GTTTTGCCGTGTTGCCCAGGCTGGTAGAT CG3'

Second TBAXS1 transcriptome is given:

>TRINITY_DN22549_c0_g1_i1

5'AAATAAGCATACGCATGGAAGAATCAC TCAGATTTTTATGTTAAATAGGAGGAACT TAGA

AAACACCAAGTGTGGATTTGGAGAATTT TGTAAAACTTAACCAAAGACAATGCCTAA TCA

CATTGAGGGCAACATAAGTGGCACTATGT GTGTCATCGGCTCAACAGTTCATTCATCA TC

ATCGGGATCTAACAAAATGACACATTGTA GGCATAATCATAACAGGACTCGGCGTAGG TT

ATCAGCAACAGCTATGATTGGAGTACTCG GAGGA3'

At last we have a special look on the PECAM1 transcriptome sequence which was found in Ophiocomina nigra genome,It exists also in Antedon bifida one :

5'ATATATCATATATGATATAGTACCTTT GTTATATATCATAATACATATAAATGTGT

ATTA

TGTTATCTATAATTATATAATTTCATATA TAAGATGTATAATATGTATCATATATTAT AT

ATGTTATGTAATATATATAGTATATATAA GATGACACAGGATAAATATTATATACTA TGA
CATATAAAATATATGAGGTTATATGTTA CATATAAGGCATAGCACATAACATGTAA TATA

TATCATATATAATTTTTTTTTAGACAGAA TCTTGTCCTGTTGCACAGGGTGGGGTAC AAT

GGCGCCATCTTTGCTCACTGCAACTTCTG CCTCACGGGTCCAAGCGATTGTCCTCCCT $\mathrm{CA}$

GCCTCCCAGGTAGCTGGGACTACACCAC ACTGGGACTACACCAGCTGCCACCATGC CTAG

CTAATTTTTGTATTTTTGGTAGAGACAGG GTTTTGCCGTGTTGCCCAGGCTGGTAGAT CG

G3'

\section{Discussion AND CONCLUSION}

Thromboxane A2 gene, we found in ophuirids(Echinodermata) induces a cytokine in human ( Ref 5). Thromboxane A2 produced by activated platelets, has prothrombotic properties. It stimulates activation of new platelets as well as increases platelet aggregation (Ref.5). Pecam1,we found also in ophuirids and crinoïds , has a special rôle in vascular biology and platelet function in human ( Ref.6).

Genomic results assert the evidence of :

a) a new cytokine in invertebrate: the thromboxane

b) a new gene in these last ones : the Pecam1 gene

Furthermore T.EM results ( Ref.1 Fig.1) show structures which resemble blood platelets. In conclusion, it was clearly shown that platelets ,Pecam1 gene and thromboxane cytokine coexist in Echinodermata: It's of special interest in Comparative Hematology.

At our knowledge red blood cells don't exist in Invertebrates but just lymphocytes and platelets!

\section{Evidence of Platelets in Echinodermata}

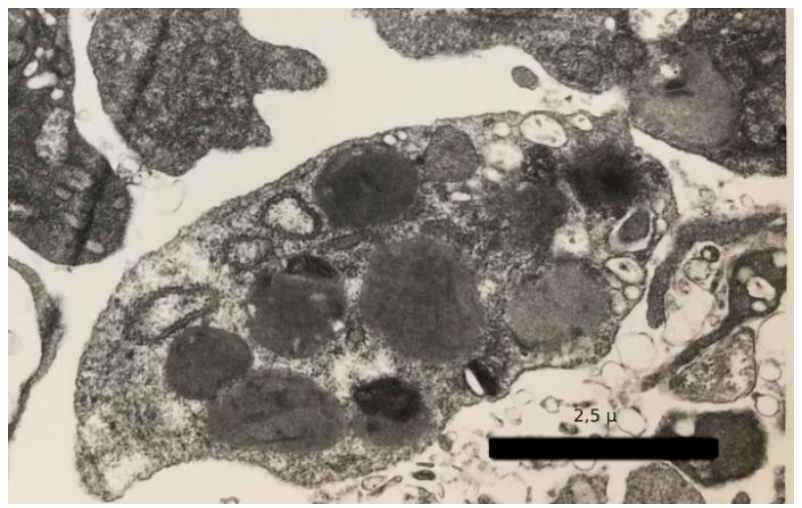

Figure 1 
Platelets, Pecam1 Gene, Thromboxane Genes, in Invertebrates

\section{REFERENCES}

[1] Leclerc M.(2020) «Platelet's problem in Echinodermata » IBBJ ( 2020) submitted

[2] Leclerc M. (2018) «A new gene in Ophiocomina nigra: An ophuirid Igkappa gene » J.Appl.Biotechnol. Bioeng. 5(5) : 303-304

[3] Grabherr M.G,B.J Haas, M.Yassour, J.Z Levin, D.A Thompson, Ido Amit et al.1 (2011) «Fulllength transcriptome assembly from RNA-Seq data without a reference genome » Nature Biotechnology 29 : 644-652
[4] Altschul S.F, W.Gish, W Miller, E.W Mijers and D.J Lipman (1990) «Basic local alignment search tool » J. Mol.Biol 215 (3) : 403-410

[5] Carter A.B, M.M Monick and G.W Hunninghake (1999) «Both Erk and p38 kinases are necessary for cytokine gene transcription » Am.J.Respir.Cell. Mol. Biol. 20:751-758

[6] Woodfin A. et al(2007) « Multi-functional Molecule in inflammation and vascular Biology » Artherioscl. Thromb. Vasc. Biol. 27:2514-2523

Citation: Michel Leclerc, "Platelets, Pecaml Gene, Thromboxane Genes, in Invertebrates", International Journal of Research Studies in Medical and Health Sciences. 2020; 5(4): 12-14.

Copyright: (c) 2020 Michel Leclerc, This is an open-access article distributed under the terms of the Creative Commons Attribution License, which permits unrestricted use, distribution, and reproduction in any medium, provided the original author and source are credited. 